\title{
Multi-Way and Poly-Phase Wideband Differential Phase Shifter Based on Metamaterial Technology
}

\author{
A. Hamidia ${ }^{1}$, M. Amin Honarvar ${ }^{1}$ and Bal S. Virdee ${ }^{2}$ \\ ${ }^{1}$ Department of Electrical Engineering, Najafabad Branch, Islamic Azad University, Najafabad, Iran \\ ${ }^{2}$ School of Computing \& Digital Media, Center for Communications Technology, London Metropolitan University, \\ London, United Kingdom
}

\begin{abstract}
This paper presents multi-way and poly-phase differential phase shifter (DPS) based on metamaterial technology to realize delay lines of equal length. The proposed phase shifter provides the required phase shift relative to the reference line over a wide bandwidth. Several DPS phase shifter designs were fabricated and tested to verify their performance. Measured results show that the proposed phase shifter has phase deviation of less than $\pm 4^{\circ}$ and return-loss better than 10-dB with an insertion-loss of less than $1 \mathrm{~dB}$ across 2.2 to $4.4 \mathrm{GHz}$.
\end{abstract}

Keywords: Differential phase shifter (DPS), wideband, metamaterials, stepped impedance resonator (SIR).

\section{Introduction}

Differential phase shifter (DPS) structures are widely used in different microwave systems such as phased-array antennas and adaptive beamforming systems [1], [2] to provide constant phase difference between two parallel paths. Conventional differential phase shifters are composed of a reference line and a delay line. DPS usually require different reference lines to provide various differential phase shifts over a specified frequency range. This results in both complex multi-way and poly-phase structures that are bulky. Additionally, in a conventional DPS the reference and delay lines are of different lengths that precludes dense integration to realize a more compact wireless communication system. Ideally, DPS should provide useful shift values with small phase deviation, operate over a wide frequency range, are low-loss and compact devices.

Traditional Schiffman phase shifters use edge-coupled lines to provide a $90^{\circ}$ phase shift however they suffer from undesirably high phase deviation typically of $\pm 10^{\circ}$ [3]. Also, tightcoupling is necessary to achieve a large fractional bandwidth of about $80 \%$. In [4] it has been shown acceptable phase ripple can be achieved using a $90^{\circ}$ phase shifter with T-shaped openstub loaded transmission-line. This phase shifter achieves a fractional bandwidth of $82 \%$ with a $\pm 6.4^{\circ}$ phase ripple. In [5] it is shown that by substituting the open-stub with a pair of multisection radial stubs a wider bandwidth can be realized. In [6], a wideband phase shifter is implemented on a multilayer substrate using an elliptical-shaped broadside coupled structure that exhibits a phase shift range of $30^{\circ}-90^{\circ}$. In [7] it is shown that by loading the phase shifter with reactive elements the phase shift can be increased to $90^{\circ} \pm 4^{\circ}$. The fractional bandwidth of this phase shifter is $80 \%$. In [8], microstrip slot-line transition is used to realize a wideband phase shifter on a single layer of substrate. This phase shifter able to provide phase shifts in the range 
of $45^{\circ}-90^{\circ}$ with minimal loss in the C-band and is relatively small. However, its differential phase stability is compromised. In [9], a single layer wideband phase shifter is proposed that provides a phase range of $45^{\circ}-180^{\circ}$. The device uses an L-shaped network combined with one section of coupled lines to obtain a fractional bandwidth of $100 \%$ but it has a high phase deviation of $\pm 8^{\circ}$. In [10] a $90^{\circ}$ phase shifter is designed to operate across $3 \mathrm{GHz}$ to $10 \mathrm{GHz}$ with phase error of $\pm 5^{\circ}$ by using two composite right/left handed (CRLH) transmission lines. In [11], a multi-way poly-phase DPS is reported. This phase shifter uses feed-forward coupled line sections as the common component. However, in this design by increasing phase shift values the length of the main line correspondingly increase [12], [13]. In [14], an equal length multi-way differential phase shifter based on metamaterials is presented. The phase shifter uses complementary split-ring resonators (CSRRs) to provide arbitrary phase shifts across a bandwidth of $65 \%$. In the aforementioned phase shifter structures, the reference and main lines are of different lengths, and the length of main line is affected by the magnitude of the required phase shift.

This paper presents a new configuration of an equal length multi-way and poly-phase DPS based on metamaterial structures. The degree of phase shift is only determined by the parameters of the metamaterial structure Unlike conventional transmission-lines the physical properties of metamaterial structures are independent of frequency. This property is exploited here in the design of compact phase shifters. Phase shifters based on metamaterial technology are realized with three different phase shifts of $60^{\circ}, 75^{\circ}$ and $90^{\circ}$ that operate over 2.2 to $4.4 \mathrm{GHz}$ for WiMAX and Bluetooth applications. Compared to other phase shifters based on SRR in [15] that provide a limited phase shift of $34^{\circ}$ across a narrowband of $5.85 \mathrm{GHz}$ to $6.05 \mathrm{GHz}$, the proposed structure can provide larger phase shifts and is significantly smaller. The performance of the phase shifter was verified practically. The detailed equivalent circuit model and theoretical analysis of the proposed DPS are presented in section 2. In section 3, the design configuration of the proposed DPS is described. The theoretical results are verified with experimental results in section 4 , and the paper is concluded in section 5 .

\section{Design Theory and Analysis}

A standard uniform microstrip transmission-line which is loaded with a square SRR slot in the ground-plane is known to operate over a narrow bandwidth. Therefore, to improve its bandwidth performance of a standard uniform transmission-line structure it is modified as depicted in Fig. 1. It comprises of a unique stepped impedance split-ring resonator (SI-SRR), which widens the bandwidth through broadband matching. SI-SRR encloses a smaller ring resonator that is connected to it centrally, which creates a transmission zero. To improve the return-loss the input and output feedlines are connected to each other with a U-shaped transmission-line. The structure includes two circular split-ring resonators (CSRRs) near the input/output ports. SI-SRR and the two CSRRs determine the upper and lower cutoff frequencies as well as the phase of the proposed microstrip structure. The phase shift of the structure can be finely controlled by changing the radius of the two CSRRs. 
The structure in the top and bottom layers represent metamaterial phase alignment network that are used to realize equal physical lengths of the reference and the delay lines. The two CSRRs can finely control the electrical length of a transmission-line, and consequently different phase shifts can be achieved by simply changing the radius of the metamaterial phase alignment network without altering any other parameters of the main and the reference lines. The advantage of this technique is marginal effect on the physical length of the transmission-line. The metamaterial CSRR configuration and its equivalent lumped element are shown in Fig. 2.

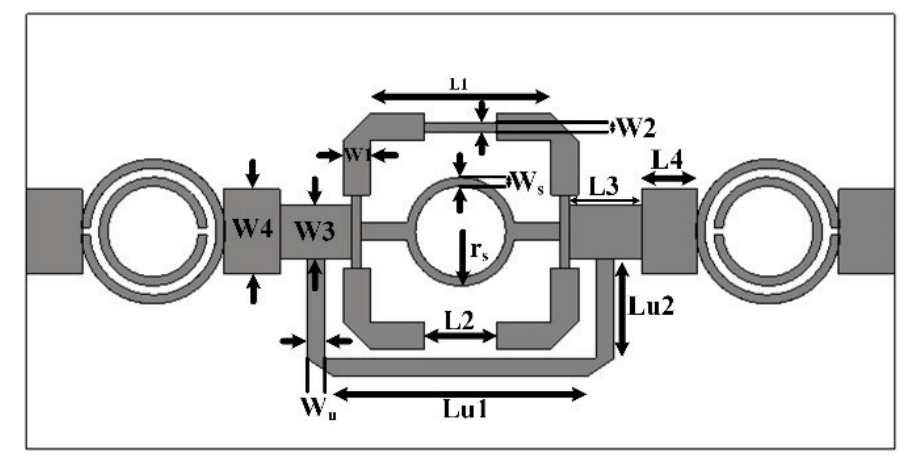

(a)

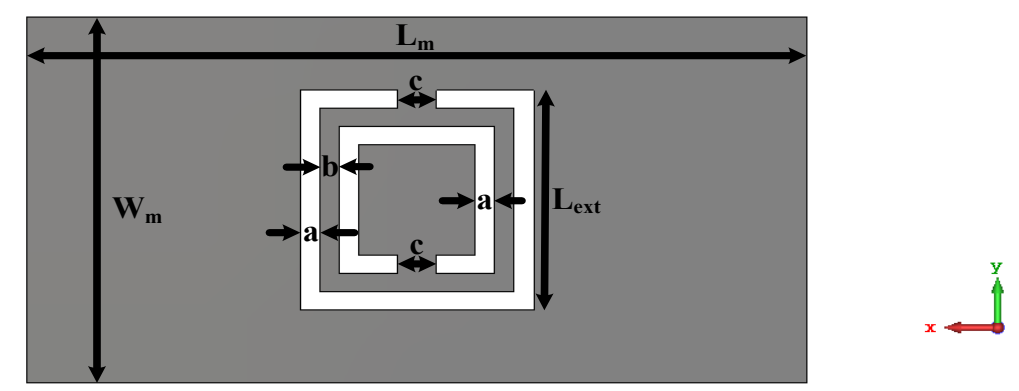

(b)

Fig. 1. Geometry of the proposed phase shifter based on metamaterial technology, (a) Top layer of main lines, and (b) Bottom layer includes a square CSRR.

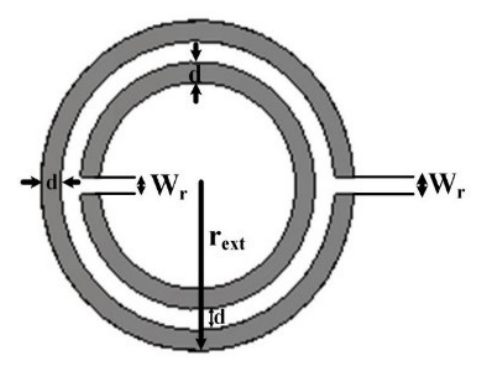

(a)

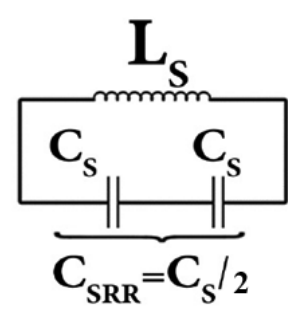

(b)

Fig. 2. (a) CSRR configuration, and (b) Equivalent lumped element model.

Reflection $\left(\mathrm{S}_{11}\right)$ and transmission $\left(\mathrm{S}_{21}\right)$ coefficients were used to retrieve the permeability of SRR in Fig. 2(a) based on the approach described in [16] using the following equation: 


$$
n=\frac{1}{j K_{o} d} \log \left[\frac{S_{21}}{1-S_{11}\left(\frac{z-1}{z+1}\right)}\right]
$$

Where $K_{o}$ and $d$ are the wave vector of the incident wave and the thickness of the substrate, respectively. $z$ is impedance of the microstrip-line and $n$ represents the refractive index. The permeability $\mu$ can then be computed from:

$$
\mu=n z
$$

The S-parameters response and extracted permeability of the SRR in Fig. 3 show the SRR has negative permeability around its resonance frequency.

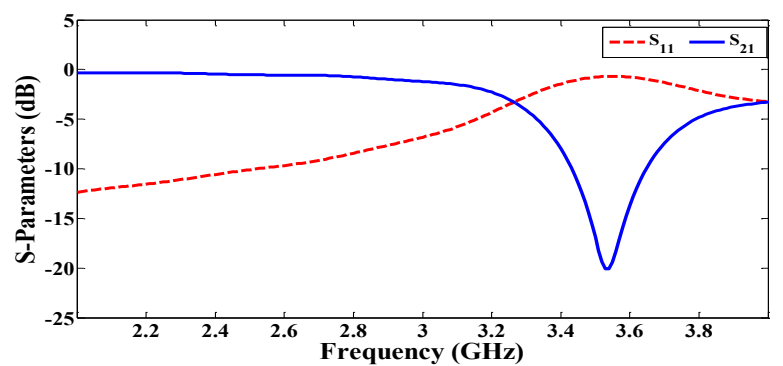

(a)

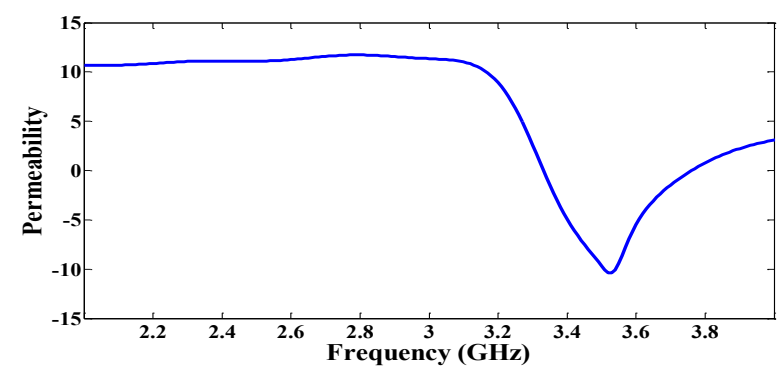

(b)

Fig. 3. (a) S-parameter response of the SRR, and (b) extracted permeability $(\mu)$.

The simplified equivalent circuit model of the proposed DPS in Fig. 1 is shown in Fig. 4. The structure in the middle is represented by the equivalent circuit in section $\mathrm{P}_{1}$, where the ground-plane square SRR slot is represented by inductance $L_{c}$ and $C_{c}$. In part, $P_{1}$ the parameters $\mathrm{L}_{\text {eq }}$ and $\mathrm{C}_{\text {eq }}$ represent the inductive and capacitive effects resulting from the SI-SRR, central ring resonator, and U-shaped transmission-line. The equivalent circuit model of the ground-plane square SRR slot is electrically coupled to SI-SRR via capacitance C. SRRs at the input and output are represented by the equivalent circuit in sections $\mathrm{P}_{2}$.

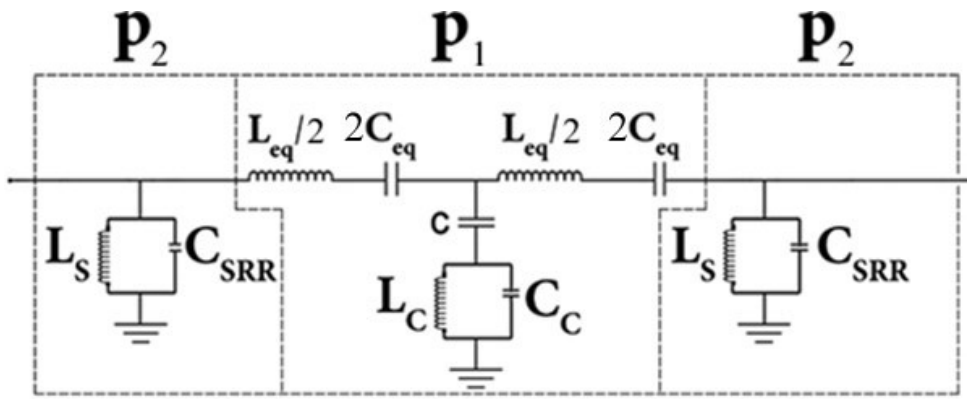

Fig. 4. Simplified equivalent circuit model of the proposed DPS constituted from the phase alignment network composed of $P_{1}$ and $P_{2}$.

The electrical length of section $\mathrm{P}_{1}$ and its characteristic impedance can be determined from the following equations [14]: 
$\cos \left(\theta_{\mathrm{P}_{1}}\right)=1+\frac{\mathrm{z}_{\mathrm{S}}(\mathrm{j} \omega)}{\mathrm{z}_{\mathrm{p}}(\mathrm{j} \omega)}$

$\mathrm{Z}_{\mathrm{P}_{1}}=\sqrt{\mathrm{Z}_{\mathrm{s}}(\mathrm{j} \omega)\left[\mathrm{Z}_{\mathrm{s}}(\mathrm{j} \omega)+2\left(\mathrm{Z}_{\mathrm{p}}(\mathrm{j} \omega)\right)\right]}$.

Where $Z_{s}$ and $Z_{p}$ represent the series and shunt impedances, respectively, in the equivalent $T$ circuit model. The characteristic impedance and electrical length are given by

$\theta_{P_{1}}=\cos ^{-1}(1)+\frac{c\left(\omega^{2} \text { LeqCeq }-1\right)\left(1-\omega^{2} L_{c} C_{c}\right)}{2 \operatorname{Ceq}\left[\left(\omega^{2} L_{c} C_{c}-1\right)+\omega^{2} L_{c} C\right]}$

$\mathrm{Z}_{\mathrm{P}_{1}}=\sqrt{\frac{\left(\omega^{2} \mathrm{LeqCeq-1}\right)}{\mathrm{C}_{\mathrm{eq}}}\left[\frac{1}{\omega^{2} \mathrm{C}}+\frac{\mathrm{L}_{\mathrm{c}}}{\left(\omega^{2} \mathrm{~L}_{\mathrm{c}} \mathrm{C}_{\mathrm{c}}-1\right)}-\frac{\left(\omega^{2} \mathrm{LeqCeq}-1\right)}{\left(\omega^{2} \mathrm{~L}_{\mathrm{c}} \mathrm{C}_{\mathrm{c}}-1\right)}\right]}$

Component values for part $\mathrm{P}_{1}$ and $\mathrm{P}_{2}$ were extracted using the equations in [17-20] for three main lines to provide a phase shift of $60^{\circ}, 75^{\circ}$ and $90^{\circ}$, which are in Table 1.

Table 1: Extracted lumped components of main lines for phase shifts of $60^{\circ}, 75^{\circ}$ and 90 .

\begin{tabular}{|c|c|c|c|}
\hline $\boldsymbol{\Delta} \boldsymbol{\varphi}$ & $\mathbf{6 0}^{\circ}$ & $\mathbf{7 5}^{\circ}$ & $\mathbf{9 0}^{\circ}$ \\
\hline $\mathrm{L}_{\mathrm{eq}}(\mathrm{nH})$ & 0.007 & 0.007 & 0.007 \\
\hline $\mathrm{C}_{\mathrm{eq}}(\mathrm{pF})$ & 0.0034 & 0.0034 & 0.0034 \\
\hline $\mathrm{L}_{\mathrm{c}}(\mathrm{nH})$ & 7.72 & 7.72 & 7.72 \\
\hline $\mathrm{C}_{\mathrm{c}}(\mathrm{pF})$ & 0.4 & 0.4 & 0.4 \\
\hline $\mathrm{C}_{(\mathrm{pF})}$ & 0.5 & 0.5 & 0.5 \\
\hline $\mathrm{L}_{\mathrm{s}}(\mathrm{nH})$ & 2.24 & 1.96 & 1.56 \\
\hline $\mathrm{C}_{\text {SRR }}(\mathrm{pF})$ & 1.06 & 0.95 & 0.86 \\
\hline
\end{tabular}

\section{Parametric Study}

Without perturbing the metamaterial phase alignment networks in Fig. 1 the bandwidth of the proposed differential phase shifter can be adjusted by altering the dimensions of $\mathrm{L}_{2}$ and $\mathrm{W}_{3}$, while keeping all other parameters are fixed as shown in Fig. 5(a). There is no change in the return-loss from $1.5 \mathrm{GHz}$ to $2.5 \mathrm{GHz}$ for change in $\mathrm{L}_{2}$ and $\mathrm{W}_{3}$. When $\mathrm{L}_{2}$ and $\mathrm{W}_{3}$ are $2 \mathrm{~mm}$ and 3 $\mathrm{mm}$, respectively, the return-loss minima occur at around $3.35 \mathrm{GHz}$. However, the minima shifts to $4 \mathrm{GHz}$ when $\mathrm{L}_{2}$ and $\mathrm{W}_{3}$ are $5 \mathrm{~mm}$ and $3.5 \mathrm{~mm}$, respectively. According to Fig. 5(b), the dimensions of the $\mathrm{L}_{2}$ and $\mathrm{W}_{3}$ have virtually no effect on the phase response between $2.2 \mathrm{GHz}$ to $4 \mathrm{GHz}$. However, in the proposed DPS structure the adjustment of the phase angle can be implemented by altering a single parameter, i.e. the radius of the phase alignment network. Fig. 6 reveals the slope of the phase shifts slightly towards lower frequency as $r_{\text {ext }}$ is increased, and there is a moderate change in return-loss. Radius of ring $\left(\mathrm{r}_{\text {ext }}\right)$ has no impact on the bandwidth of structure. 


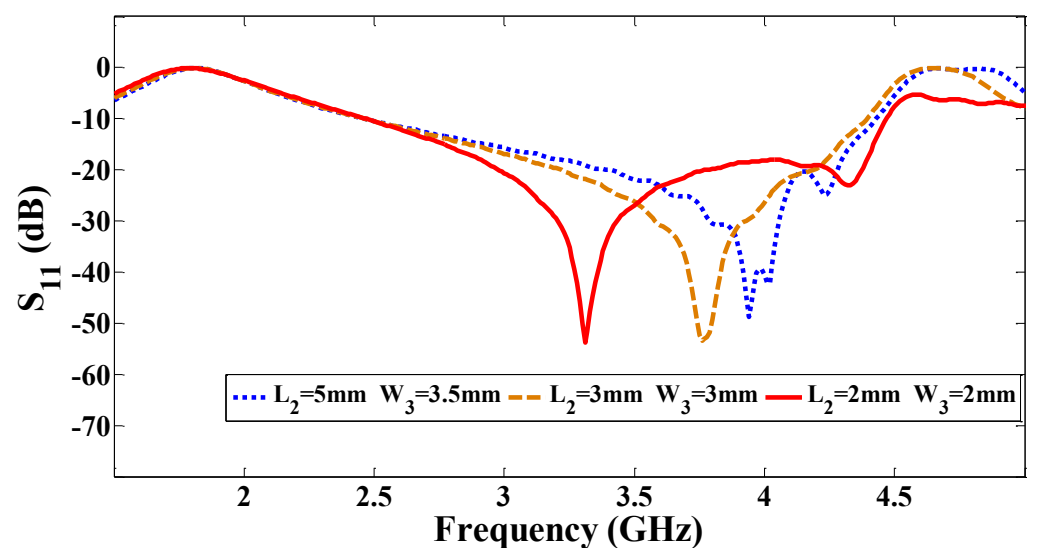

(a)

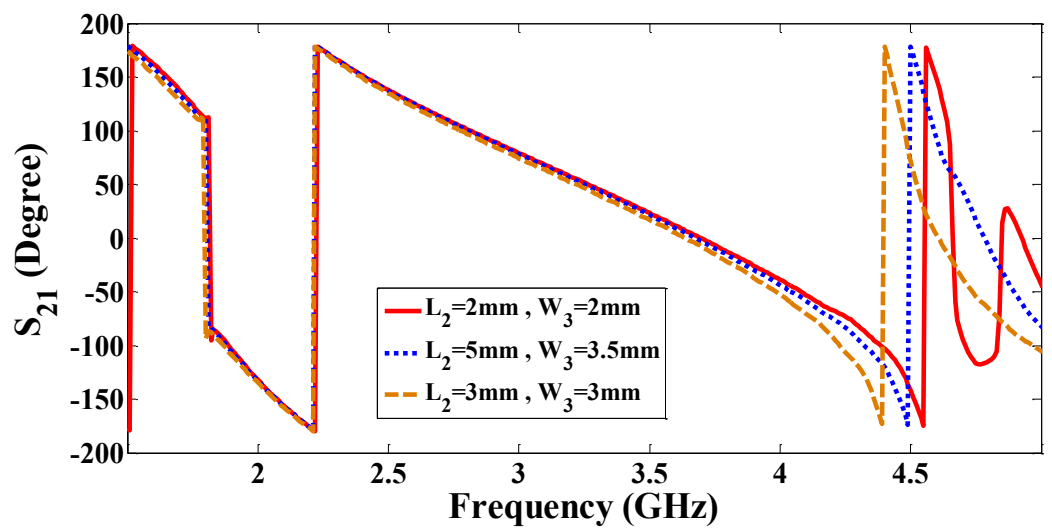

(b)

Fig. 5. Simulated return-loss and transmission angle frequency response of DPS as a function of $L_{2}$ and $W_{3}$, (a) $S_{11}(d B)$, and (b) $\angle S_{21}\left(^{o}\right)$

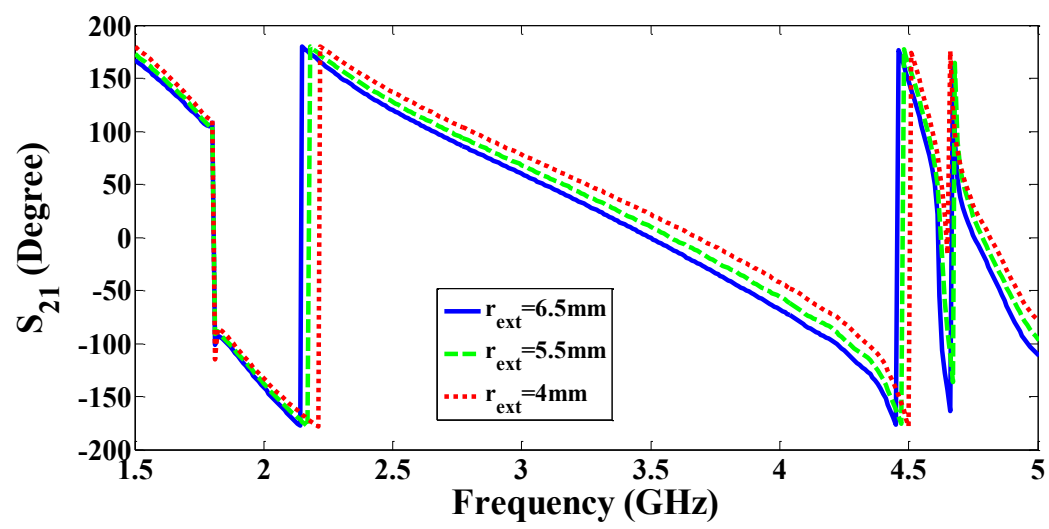

(a) 


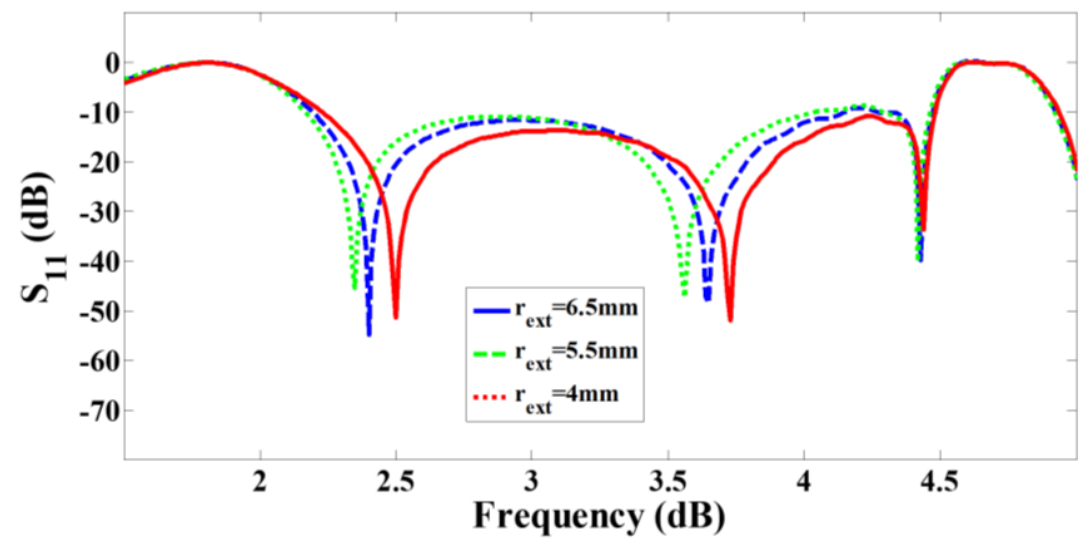

(b)

Fig. 6. Simulated transmission angle and return-loss frequency response of DPS as a function of $r_{\text {ext, }}(a) \angle S_{21}\left({ }^{\circ}\right)$, and (b) $S_{11}(d B)$.

Fig. 7 shows how the resonant frequency and permeability of the SRR are affected by $\mathrm{r}_{\text {ext. }}$. It shows regions in the frequency band where the permeability is negative and how this shift with change in $r_{\text {ext. }}$.

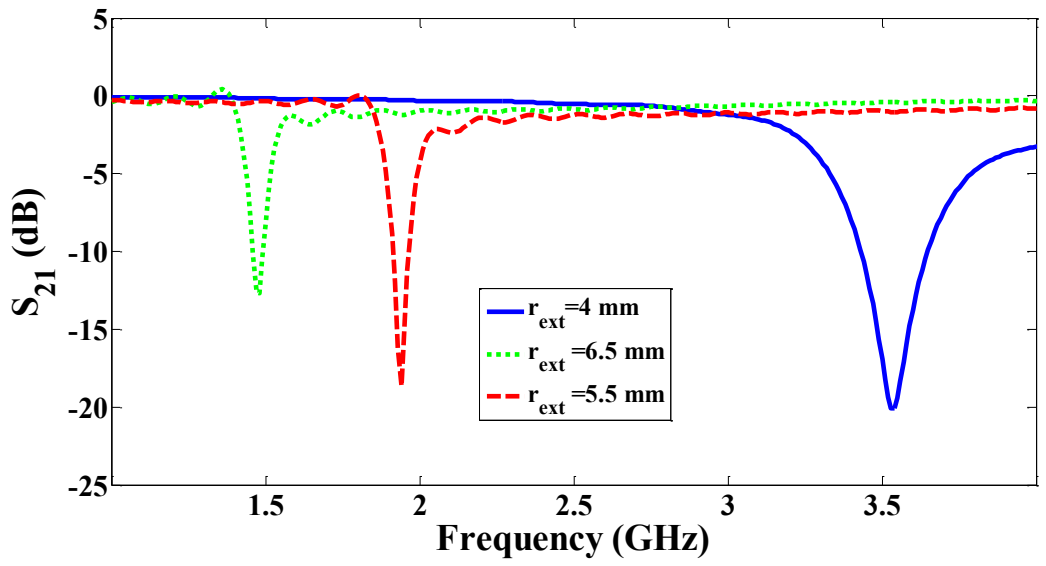

(a)

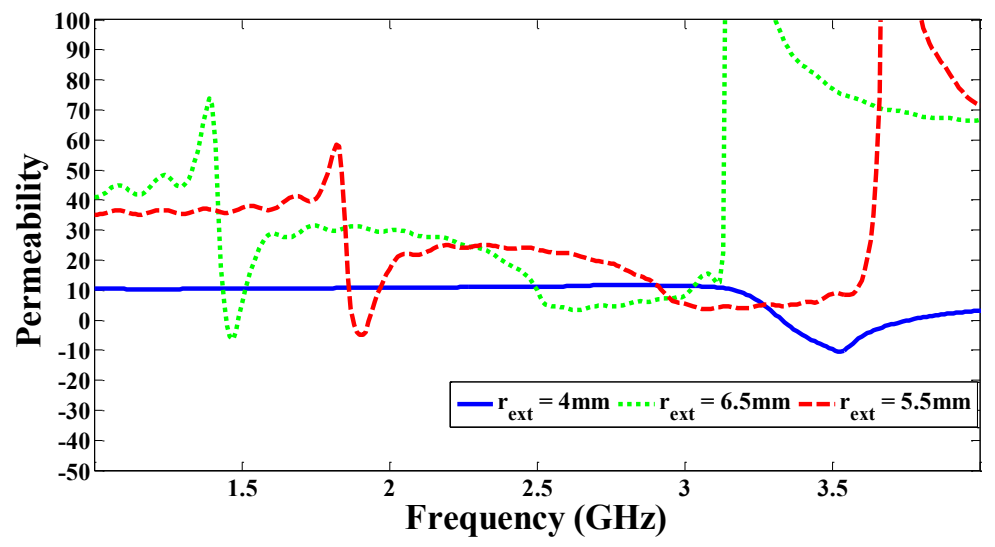

(b)

Fig. 7. Effect of $r_{\text {ext. }}$ on the SRR's (a) transmission response, and (b) permeability. 


\section{Experimental Results and Discussion}

As mentioned earlier the proposed DPS was designed and fabricated on Rogers Duroid 5870 substrate with a relative permittivity $\left(\varepsilon_{r}\right)$ of 2.33 , loss-tangent of 0.0012 and a thickness $(h)$ of $1.575 \mathrm{~mm}$. CST Microwave Studio ${ }^{\mathrm{TM}}$ software was used to optimize the DPS's performance. Physical dimensions of the three phase shifters are given in Table 2. Dimensions of two metamaterial phase alignment networks to provide phase shifts of $60^{\circ}, 75^{\circ}$ and $90^{\circ}$ are given in Table 3. Fig. 8 shows a photograph of the three delay lines and a reference line that were fabricated and measured.

Table 2: Dimensions of the DPS main lines for phase shifts of $60^{\circ}, 7^{\circ}$ and 90 . (Units in mm)

\begin{tabular}{|c|c|c|c|}
\hline $\boldsymbol{\Delta \varphi}$ & $\mathbf{6 0}^{\circ}$ & $\mathbf{7 5}^{\circ}$ & $\mathbf{9 0}^{\circ}$ \\
\hline $\mathrm{L}_{1}$ & 10 & 10 & 10 \\
\hline $\mathrm{L}_{2}$ & 4 & 4 & 4 \\
\hline $\mathrm{L}_{3}$ & 4 & 4 & 4 \\
\hline $\mathrm{L}_{4}$ & 0.5 & 1.5 & 3 \\
\hline $\mathrm{L}_{\mathrm{u} 1}$ & 15 & 15 & 15 \\
\hline $\mathrm{L}_{\mathrm{u} 2}$ & 5.5 & 5.5 & 5.5 \\
\hline $\mathrm{W}_{1}$ & 1.5 & 1.5 & 1.5 \\
\hline $\mathrm{W}_{2}$ & 0.5 & 0.5 & 0.5 \\
\hline $\mathrm{W}_{3}$ & 3 & 3 & 3 \\
\hline $\mathrm{W}_{4}$ & 4.68 & 4.68 & 4.68 \\
\hline $\mathrm{W}_{\mathrm{u}}$ & 1 & 1 & 1 \\
\hline $\mathrm{W}_{\mathrm{s}}$ & 0.5 & 0.5 & 0.5 \\
\hline $\mathrm{r}_{\mathrm{s}}$ & 3 & 3 & 3 \\
\hline $\mathrm{l}_{\mathrm{m}}$ & 48 & 48 & 48 \\
\hline $\mathrm{W}_{\mathrm{m}}$ & 24 & 24 & 24 \\
\hline $\mathrm{a}$ & 1.2 & 1.2 & 1.2 \\
\hline $\mathrm{b}$ & 1.2 & 1.2 & 1.2 \\
\hline $\mathrm{c}$ & 2.4 & 2.4 & 2.4 \\
\hline $\mathrm{L}_{\mathrm{ext}}$ & 14.4 & 14.4 & 14.4 \\
\hline
\end{tabular}

Table 3: Dimensions of metamaterial phase alignment network main lines for phase shifts of $60^{\circ}, 75^{\circ}$ and $90^{\circ}$. (Units in mm)

\begin{tabular}{|c|c|c|c|}
\hline$\Delta \boldsymbol{\varphi}$ & $\mathbf{6 0}^{\circ}$ & $\mathbf{7 5}^{\circ}$ & $\mathbf{9 0}^{\circ}$ \\
\hline $\mathrm{r}_{\mathrm{ext}}$ & 6.5 & 5.5 & 4 \\
\hline $\mathrm{d}$ & 0.5 & 0.5 & 0.5 \\
\hline $\mathrm{W}_{\mathrm{r}}$ & 0.4 & 0.4 & 0.4 \\
\hline
\end{tabular}




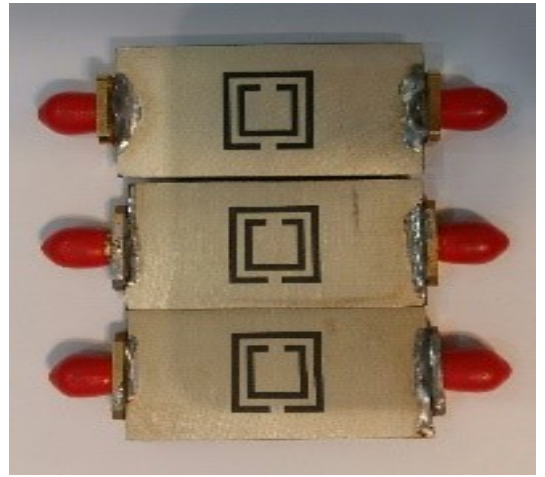

Bottom side

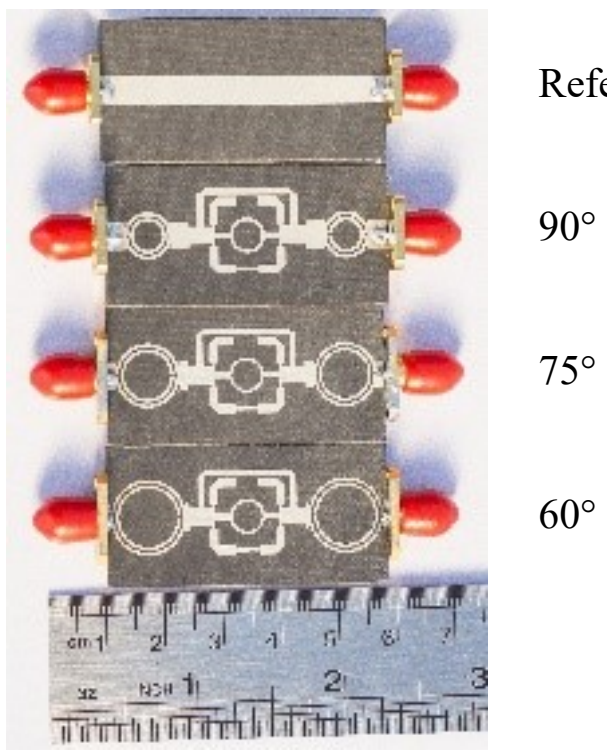

Top side

Fig. 8. Photograph of the fabricated phase shifters for arbitrary phase shift values.

The simulated and measured frequency S-parameter response of the phase shifters in Fig. 9 show that the return-loss and insertion-loss are better than $10 \mathrm{~dB}$ and less than $0.5 \mathrm{~dB}$, respectively, over 2.2 to $4.4 \mathrm{GHz}$. There is also good agreement between the simulated and measured results.

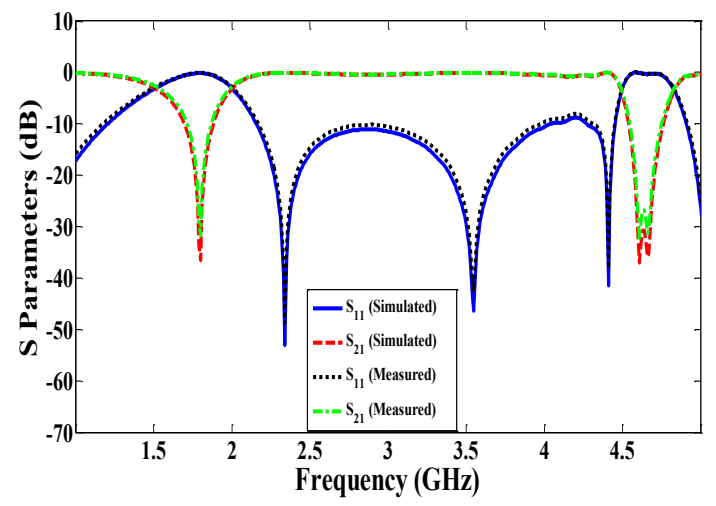

(a)

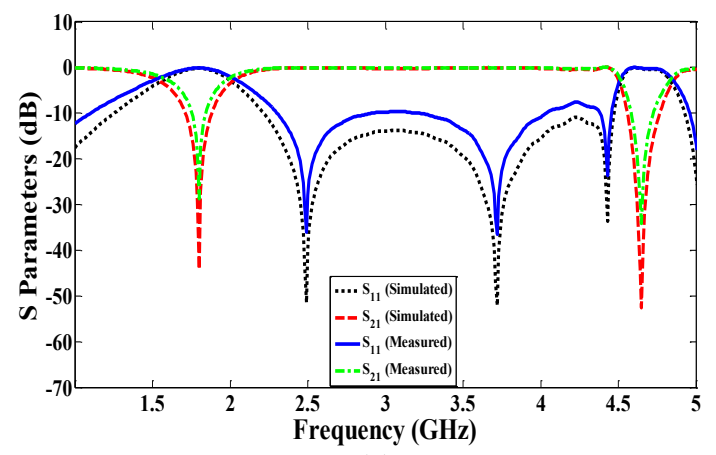

(c)

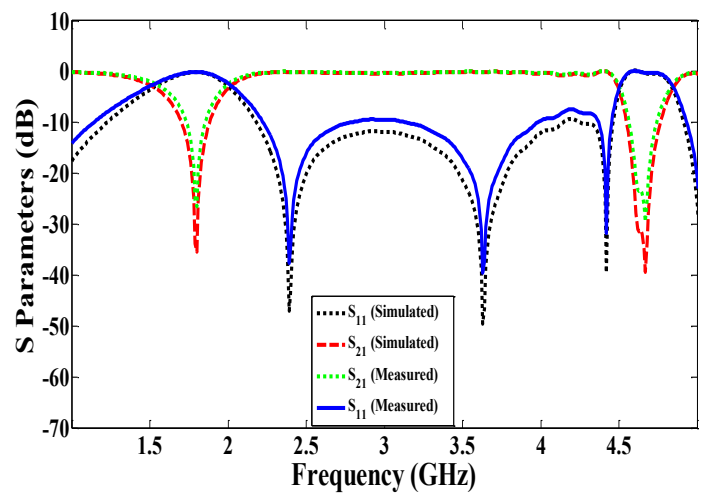

(b) 
Fig. 9. S-parameter response of the three phase shifters, (a) $60^{\circ}$ delay line, (b) $75^{\circ}$ delay line, and (c) $90^{\circ}$ delay line.

The phase differences of the proposed DPSs are shown in Fig. 10. The delay lines maintain constant phase shifts of $60^{\circ}, 75^{\circ}$ and $90^{\circ}$ across a bandwidth of 2.2 to $4.4 \mathrm{GHz}$. The measurements show that the phase shifters have less than $4^{\circ}$ differential phase stability.

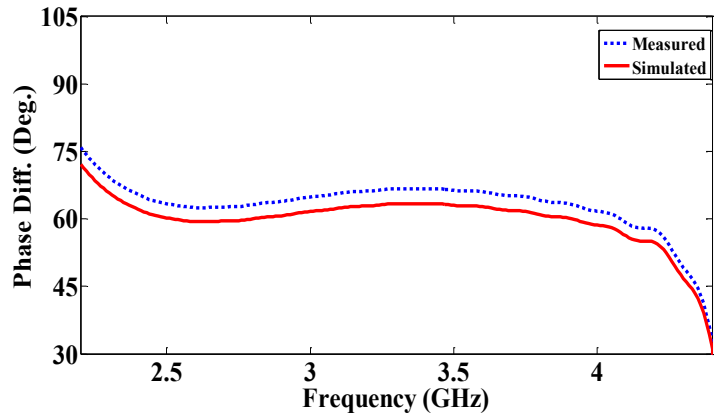

(a)

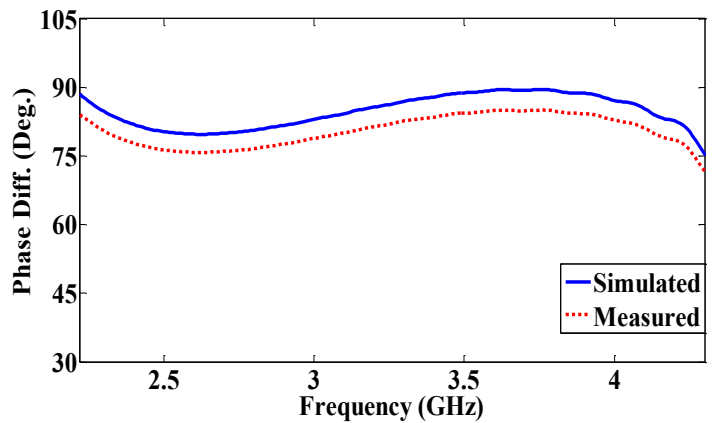

(c)

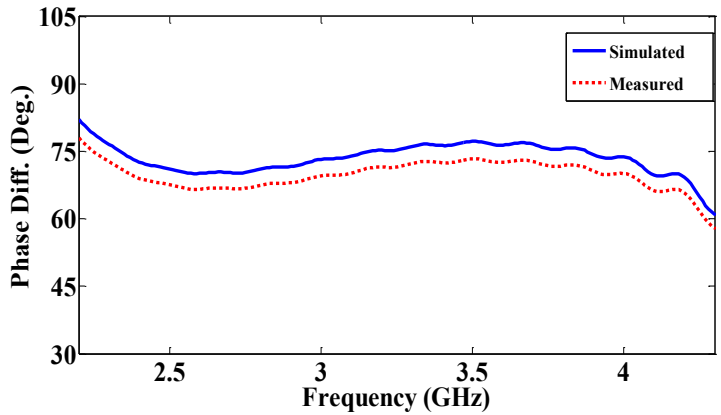

(b)

Fig. 10. Simulated and measured phase response of the DPSs, (a) $60^{\circ}$, (b) $75^{\circ}$, and (c) $90^{\circ}$.

The proposed DPS design is compared with the other DPSs in Table 4, which reveals that the proposed DPS achieves better results compared with the previously reported DPSs except that its bandwidth of $88 \%$ is lower than the structures in [5], [9] \& [10]. This is because these structures have a longer main line that supports a larger phase shift. The proposed DPS is compact as all lines are of equal length that is achieved with metamaterial phase alignment networks.

TABLE 4: Comparison of the proposed phase shifter with previous works

\begin{tabular}{|c|c|c|c|c|c|c|c|c|c|c|}
\hline Ref. & $\begin{array}{l}\text { Multi-way } \\
\text { poly-phase }\end{array}$ & $\begin{array}{l}\text { Phase } \\
\text { shift } \\
\text { values }\left(^{\circ}\right)\end{array}$ & $\begin{array}{l}\text { Universal } \\
\text { Ref. line }\end{array}$ & $\begin{array}{l}\text { Equal } \\
\text { line } \\
\text { lengths }\end{array}$ & $\begin{array}{l}\text { Equal length } \\
\text { ref. line }\end{array}$ & BW (\%) & $\begin{array}{l}\text { Metamaterial } \\
\text { phase Align. } \\
\text { Net. }\end{array}$ & $\begin{array}{l}\mathrm{IL} \\
(\mathrm{dB})\end{array}$ & $\begin{array}{l}\text { Max. } \\
\text { PD } \\
\left({ }^{\circ}\right)\end{array}$ & $\begin{array}{l}\text { Size } \\
\left(\chi_{0}\right)\end{array}$ \\
\hline [4] & No & 90 & No & No & No & 82 & No & $<0.6$ & \pm 6.4 & - \\
\hline [7] & No & 90 & No & No & No & 80 & No & $<2.3$ & \pm 4 & - \\
\hline [8] & No & $45-90$ & Yes & No & No & 80 & No & $<1.1$ & \pm 4.5 & $0.42 \times 0.25$ \\
\hline [9] & No & $45-180$ & No & No & No & 100 & No & $<0.6$ & \pm 8 & $0.5 \times 0.3$ \\
\hline [11] & Yes & $\begin{array}{c}45,90 \\
180\end{array}$ & Yes & No & No & 40 & No & $<0.9$ & \pm 5 & - \\
\hline
\end{tabular}




\begin{tabular}{|c|c|c|c|c|c|c|c|c|c|c|}
\hline$[12]$ & Yes & $\begin{array}{c}45,90, \\
135\end{array}$ & Yes & No & No & 45 & No & $<0.9$ & \pm 5 & - \\
\hline$[13]$ & Yes & $45-135$ & Yes & No & No & 55.6 & No & $<0.7$ & \pm 5.8 & - \\
\hline$[14]$ & Yes & $30-90$ & Yes & Yes & No & 65 & No & $<1.24$ & \pm 5 & - \\
\hline$[15]$ & Yes & 34 & Yes & Yes & No & & No & $<1.5$ & \pm 1.5 & $4 \times 0.5$ \\
\hline $\begin{array}{l}\text { This } \\
\text { work }\end{array}$ & Yes & $60-90$ & Yes & Yes & Yes & 88 & Yes & $<1$ & \pm 4 & $0.56 \times 0.28$ \\
\hline
\end{tabular}

\section{Conclusion}

The feasibility of a novel class of equal length multi-way poly-phase wideband differential phase shifter is demonstrated. The phase shifter is based on metamaterial technology. Compared to phase shifters based on SRR reported to date the proposed structure provides larger phase shifts by simply adjusting a single parameter of the metamaterial structure and is also significantly smaller. Compared with conventional phase shifters, the proposed phase shifter has advantages of a compact design, wide frequency band of operation and offers a large range of phase shift angles. The phase angle can be accurately controlled by changing the radius of SRRs constituting the phase shifter. The phase shifter's performance was verified through measurement.

\section{References}

[1] Qu S, He D, Yang S, Nie Z., Novel parasitic microstrip arrays for low-cost active phased array applications. IEEE Trans Antennas Propag 2014; 62(4): 1731-7.

[2] Chang C, Lee R, Shih T., Design of a beam switching/steering Butler matrix for phased array system. IEEE Trans. Antennas Propag 2010; 58(2): 367-74.

[3] Schiffmann B., A new class of broad-band microwave 90- degree phase shifters. IEEE Trans Microw Theory Tech. 1958; 6(2):232-7.

[4] Zheng SY, Chan WS, Man KF., Broadband phase shifter using loaded transmission line. IEEE Microw Wireless Compon Lett 2010; 20(9): 498-500.

[5] Yeung SH, Xue Q, Man KF., Broadband $90^{\circ}$ differential phase shifter constructed using a pair of multisection radial line stubs. IEEE Trans. Microw Theory Techn 2012; 6(9): 2760-7.

[6] Khajepour S, Asadi S, Ghafarian MS, Moradi G., Design of novel wideband reflective phase shifters with wide range of phase applications. AEU-Int J Electron Commun. 2017; 71:30-6.

[7] Sorn M, Lech R, Mazur J., Simulation and experiment of a compact wideband $90^{\circ}$ differential phase shifter. IEEE Trans. Microw. Theory Techn. 2012; 60(3): 494-501.

[8] Honarvar MA, Jolani F, Dadgarpour AM, Virdee B., Compact wideband phase shifter. Int J RF and Microwave CAE 2013; 23(1): 47-51.

[9] Guo L, Zhu H, Abbosh A., Wideband phase shifter with wide phase range using parallel coupled lines and Lshaped networks. IEEE Microw Wireless Compon. Lett. 2016; 26(8): 592-4.

[10] R. Mirzavand, B. Honarbakhsh, A. Abdipour, Tavakoli, A., Metamaterial-based phase shifters for ultra wideband applications. Journal of Electromagnetic Waves and Applications 2013; 23: 1489-1496.

[11] Wong YS, Zheng SY, Chan WS., Multi-way and poly-phase aligned feed-forward differential phase shifters. IEEE Trans. Microw. Theory Techn. 2014; 62(6):1312-21.

[12] Pu XY, Zheng SY, Liu J, Li Y, Long Y., Novel multi-way broadband differential phase shifter with uniform reference line using coupled line structure. IEEE Microw. Wireless Compon. Lett. 2015; 25(3): 166-8.

[13] Xu BW, Zheng SY, Pan YM, Huang YH., A universal reference line-based differential phase shifter structure with simple design formulas. IEEE Trans Compon. Packaging Manufacturing Techn. 2017; 7(1): 123-30.

[14] Qamar Z, Zheng SY, Chan YS, Ho D., An equal-length multiway differential metamaterial phase shifter. IEEE Trans Microw. Theory Techn. 2017; 65(1):136-46.

[15] N. Boskovic, B. Jokanovic, Nesic A., Printed scanning antenna array with SRR phase shifters. 7th Int. Congress on Advanced Electromagnetic Materials in Microwaves and Optics 2013; 118-120. 
[16] T. Feng, F. Liu, W. Y. Tam and Li, J., Effective parameters retrieval for complex metamaterials with low symmetries. Exploring Physics Letter Journal, 2013; 102(1): 18003 1-6.

[17] Gil M, Bonache J, Gil I, García-García J, Martín F., Miniaturisation of planar microwave circuits by using resonant-type left-handed transmission lines. IET Microw. Antennas Propag. 2007; 1(1):73-9.

[18] Bahl I., Lumped Elements for RF and Microwave Circuits. London, U. K., Artech House; 2003.

[19] Caloz C, Itoh T., Electromagnetic Metamaterials. New Jersey, John Wiley; 2006.

[20] Y. J. Cheng, W. Hong, and K. Wu. Broadband Self-Compensating Phase Shifter Combining Delay Line and Equal-Length Unequal-Width Phaser. IEEE Trans Microw. Theory Techn. 2010; 58(1): 203-10. 